\title{
Fabrication of new ceramics nanocomposites for solar energy storage and release
}

\author{
Aseel Hadi ${ }^{1}$, Ahmed Hashim², Dalal Hassan ${ }^{3}$ \\ ${ }^{1}$ University of Babylon, College of Materials Engineering, Department of Ceramic and Building Materials, Iraq \\ ${ }^{2,3}$ University of Babylon, College of Education for Pure Sciences, Department of Physics, Iraq
}

\begin{tabular}{l}
\hline Article Info \\
\hline Article history: \\
Received Jan 24, 2019 \\
Revised Jul 12, 2019 \\
Accepted Sep 26, 2019 \\
\hline
\end{tabular}

\section{Keywords:}

Energy storage Melting time

Metals carbides

Silicon carbide

Tantalum carbide

\begin{abstract}
The carbides nanostructures have huge applications in renewable energy fields such as the saving of solar energy and release which attributed to the good their properties (thermal, electrical, mechanical, optical and chemical). So, in this paper, the solar energy storage and release of carbides nanoparticles/water for building heating and cooling applications have been investigated with different concentrations of metals carbides nanoparticles (tantalum carbide-silicon carbide). The results showed that the melting and solidification times for thermal energy storage and release decrease with an increase (TaC-SiC) nanoparticles concentrations. From the obtained results, the $\mathrm{TaC} / \mathrm{SiC}$ nanostructures/ water nano-system are considered as promising materials for solar energy storage and release with high efficiency and high gain (more than $50 \%$ compare with the water). Also, the $\mathrm{TaC} / \mathrm{SiC}$ may be used for heating and cooling fields with good performance and high gain.
\end{abstract}

This is an open access article under the $\underline{C C B Y-S A}$ license.

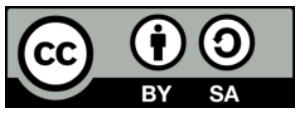

Corresponding Author:

Ahmed Hashim,

Department of Physics,

University of Babylon,

Iraq Babil Najaf road, PO Box: 4 Iraq Babylon Hilla .

Email: ahmed_taay@yahoo.com

\section{INTRODUCTION}

Modern projections forecast that the main power spending will increase to $48 \%$ during 2040. On the other hand, the reduction of relic funds in adding together to their negative shock on the surroundings has accelerated the move to energy of sustainable sources. Energies of renewable like wind, biogas, solar energy, and ocean waves have been acting a chief role in reforming the normalbalance and getting the wants of the rising people command. But, owing to the vagaries of climatic, the income of renewable energy storing has happened to imperative. This has direct require to increase sustainable and efficient methods for energy storing. Storage of energy has suited a significant branch of technology systems of renewable energy.

Thermal Energy Storage (TES) is a technology that depends on thermal energy by cooling or heating a storage space as a result the stored energy can be used at an afterward time for cooling and hea ting applications and energy production. Thermal energy storage systems are used chiefly in manufacturing processes and in buildings. Advantages with thermal energy storage in system of energy contain a raise in better reliability and overall efficiency, and it can guide to better finances, decreasing in running costs and investment [1]. TES through latent heat is one of the majority significant renewable energy storage applications. 
The thermal energy storage can classified to three necessary parts, chemical heat, latent heat, and sensible heat. Latent heat storage system is based on storage of thermal energy at the temperature of phase transition from solid to liquid stage. The fundamental role of this ability is the choice a $n$ exact (PCM) for an exacting application depend chiefly at which on temperature of melting range (change of phase) of that (PCM). Owing to the proper properties of the paraffin like nontoxic, stability, and noncorrosive can regard as an excellent options for utilizing like PCM. The disadvantage that related with using of paraffin like PCM is the small thermal conductivity [2]. Thermal energy storage can be explained as the storeroom of thermalenergy at any temperature (i.e., both, low or high) for purposes of temporary.

Thermal energy are essentially stored in three dissimilar methods which contain latent heat stora ge, sensible heat storage, and a number of physiochemical reactions consequences in the thermal storeroom. Sensible heat storage is the storeroom systems in which the heat is stored straight with no the phase changing of the material. Heat transfer fluids are used for storage of sensible heat. Energy storage frequently arises dependability and steady the energy provide which increases the energy performance systems. A storage system increases the power generated performance by load leveling; the superior efficiency tends to energy protection and improves the effectiveness of cost [3].

Agreement about the achievement of environmental energy-saving practices and policies are gradually more present at the local, international or national level. The major reasons for achievement are, on the lone hand, to decrease the gradually more elevated cost of energy reliance on fuels of fossil and, on the second hand, to decrease the polluting emissions of those fuels of fossil, which are mostly dependable for the effect of greenhouse. The present two chief advantages: the decrease of the reliance on fuels of fossil and the option of similar energy provide and require when they do not agree in time [4]. As the cruces of energy are departing to the elevated extent it is extremely important to produce the energy which is available, it may be in small mark form or it may be in the waste heat shape which is departing to sink for recycling and cooling the procedure. It is very necessary to produce the obtainable energy and create use of it for more minor heating processes. Heat is a type of power which is typically goes to the go under after the dissimilar processes concerned; a pproximately 70 to $80 \%$ of heat energy is obtainable for using.

In the majority processes, excess thermal energy is free to the atmosphere or a big body of water to total a cyclic procedure or stop overheating of facilities or components [5]. There are many researchers are working on the phase change materials, energy storage and release [6-18]. The nanocomposites have numerous applications in the areas of automobiles, microelectronic packaging, injection molded products, optical integrated circuits, packaging materials, aerospace, coatings, consumer goods, adhesives, fire-retardants [19], sensor of pressure [20, 21], optoelectronic and electronic applications [22], radiation shielding and bioenvironmental[22], sensors of humidity [23], antibacterial [24].

\section{MATERIAL AND METHODS}

The metals carbides nanoparticles/water were prepared for thermal energy storage and release with different concentrations of (tantalum carbide-silicon carbide) nanoparticles are water/ $(\mathrm{TaC})_{0.5 \mathrm{x}}-(\mathrm{SiC})_{0.5 \mathrm{x}}$ where $\mathrm{x}=0.02,0.04$ and 0.06 . The thermal energy storage and release contain the melting and solidification processes during heating and cooling. The water/(TaC-SiC) nanoparticles were used like the heat transfer, whose temperature can be varied from $30^{\circ} \mathrm{C}$ to $90^{\circ} \mathrm{C}$ with stirrer and measuring the temperature during the heating and cooling processes by digital device.

\section{RESULTS AND DISCUSSION}

Figure 1 and Figure 2 show that the curves of heating and cooling water/(TaC-SiC) nanoparticles respectively. From the figures, the times of heating and cooling reduce with increase in ratios of $(\mathrm{TaC}-\mathrm{SiC})$ nanomaterials. This is a useful method to repair the thermal conductivity of (TaC-SiC) nanoparticles. Furthermore, quicker rates of heating and cooling nanofluids would be clear to the improvement of thermal conductivity for foundation material[25-27]. 


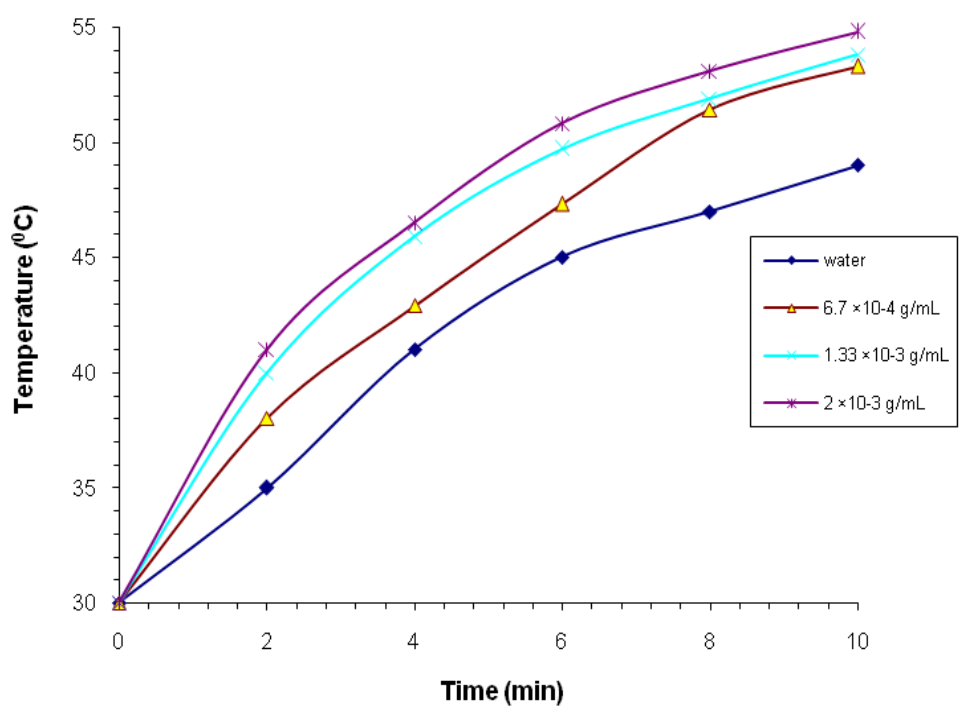

Figure 1. Melting curves of (TaC-SiC)/water

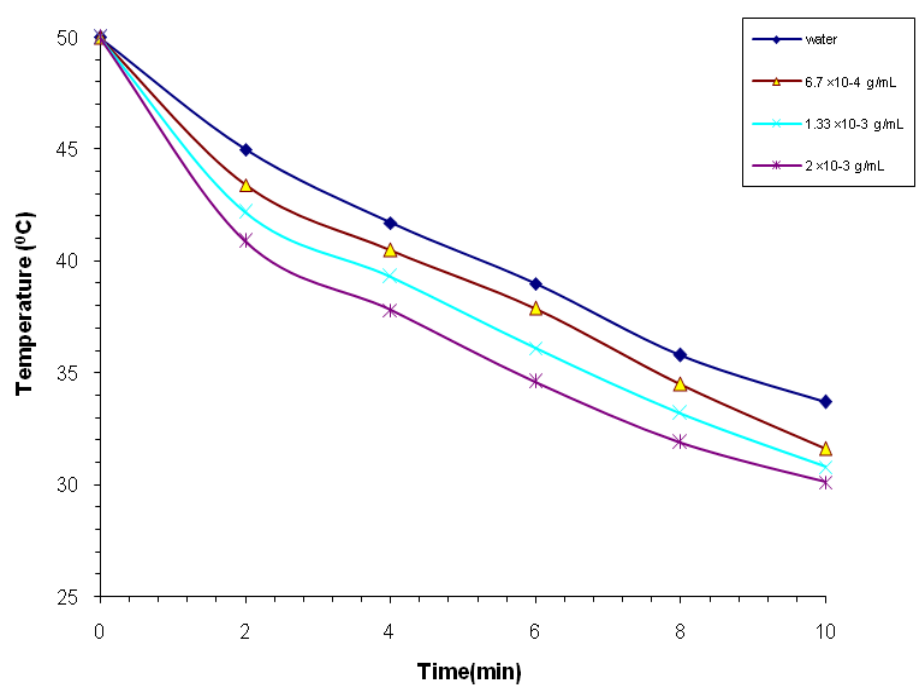

Figure 2. Solidification curves of $(\mathrm{TaC}-\mathrm{SiC}) /$ water

\section{CONCLUSION}

The water/(TaC-SiC) nanoparticles have high efficiency for thermal energy release and storage. The heating and cooling times reduce with increase in (TaC-SiC) nanoparticles ratios. The water/( $\mathrm{TaC}-\mathrm{SiC})$ nanoparticles could be considered efficient for solar water heating system.

\section{REFERENCES}

[1] Ioan Sarbu and Calin Sebarchievici, "A comprehensive review of thermal energy storage," Sustainability, vol. 10, no. 1, pp. 191, 2018.

[2] F. R. Saeed, E. C. Serban, E. Vasile, M. H. A. A. Al-Timimi, W. H. A. Al-Banda, M. Z. A. Abdullah, I. Stamatin, A. Cucu, S. M. Iordache, S. Voinea, and A. E. Balan, "Nanomagnetite enhanced paraffin for thermal energy storage applications," Digest Journal of Nanomaterials and Biostructures, vol. 12, no. 2, pp. 273-280, 2017.

[3] N. Beemkumar, A. Karthikeyan, Saravanakumar B., and Jayaprabakar J, "Performance improvement of energy storage system with nano-additivesin HTF," Frontiers in Automobile and Mechanical Engineering: IOP Conf. Series: Materials Science and Engineering, vol. 197, 2017. 
[4] Maria Elena ArceD, Miguel Ange, Alvarez Feijoo, Andres Suarez Garcia, and Claudia C. Luhrs, "Novel formulations of phase change materials-epoxy composites for thermal energy storage," Materials, vol. 11, no. $195,2018$.

[5] Santosh Chavan, Vishwanath Panwar, Rajkumar Rathod, "Review on thermal energy storage techniques," International Journal of Engineering Development and Research, vol. 3, issue 4, 2015.

[6] V. Aneesh, G. Ravikumar Solomon, "Review on heat transfer enhancement during solidification of PCM," IOSR Journal of Mechanical and Civil Engineering, National Conference on Contemporary Approaches in Mechanical, Automobile and Building sciences-2014 Karpaga Vinayaga College Of Engineering \& Technology, pp. 38-45, 2014

[7] A. Valan Arasu, Agus P. Sasmito, and Arun S. Mujumdar, "Thermal performance enhancement of paraffin wax with $\mathrm{Al}_{2} \mathrm{O}_{3}$ and $\mathrm{CuO}$ nanoparticles-a numerical study," Frontiers in Heat and Mass Transfer (FHMT), vol. 2, pp. 1-7, 2011.

[8] S. P. Jesumathy, M. Udayakumar, and S. Suresh, "Heat transfer characteristics in latent heat storage system using paraffin wax," Journal of Mechanical Science and Technology, vol. 26, no. 3, pp. 959-965, 2012.

[9] R. Senthil and P. Sundaram, "Effect of phase change materials for thermal management of buildings," International Journal of Civil Engineering and Technology, vol. 8, issue 9, pp. 761-767. 2017.

[10] Vikrant Khullar, Vishal Bhalla, and Himanshu Tyagi, "Potential heat transfer fluids (nanofluids) for direct volumetric absorption based solar thermal systems," J. Thermal Sci. Eng. Appl., vol. 10, no. 1, 2017.

[11] X. Wang , Y. He , G. Cheng, L. Shi , X. Liu, and J. Zhu, "Direct vapor generation through localized solar heating via carbonnanotube nanofluid," Energy Conversion and Management, vol. 130, 2016.

[12] A. T. Pise, A. V. Waghmare, and V. G. Talandage, "Heat transfer enhancement by using nanomaterial in phase change material for latent heat thermal energy storage system," Asian Journal of Engineering and Applied Technology, vol. 2 no. 2, pp. 52-57, 2013.

[13] Mustapha Faraji, "Investigation of the melting coupled natural convection of nano phase change material: A fan less cooling of heat sources," FDMP, vol. 13, no. 1, pp. 19-36, 2017.

[14] P. Patil and T. Dey, "Experimental study of latent heat thermal energy storage system using PCM with effect of metal configurations and nano particles," Int. J. of Current Engineering and Technology, special issue-5, 2016.

[15] A. Sciacovelli, F. Colella, and V. Verda, "Melting of PCF in thermal energy storage unit numerical investigation and effect of nanoparticle enhancement," International Journal of Energy Research, vol. 37, issue 3, pp. 1610-1623, 2013.

[16] C. L. Saw, H. H. Al-Kayiem, and A. L. Owolabi, "Experimental investigation on the effect of PCM and nano-enhanced PCM of integrated solar collector performance," WIT Transactions on Ecology and the Environment, vol. 179, 2013.

[17] R. K. Sharma, P. Ganesan, "Solidification of nano-enhanced phase change materials (NEPCM) in a trapezoidal cavity: A CFD study," Universal Journal of Mechanical Engineering, vol. 2, no. 6, pp. 187-192, 2014.

[18] S. S. Sebti, SH. Khalilarya, I. Mirzaee, S. F. Hosseinizadeh, S. Kashani, and M. Abdollahzadeh, "A numerical investigation of solidification in horizontal concentric annuli filled with nano-enhanced phase change material (NEPCM)," World Applied Sciences Journal, vol. 13, no. 1, pp. 9-15, 2011.

[19] Ahmed Hashim and Ali Jassim, "Novel of biodegradable polymers-inorganic nanoparticles: Structural, optical and electrical properties as humidity sensors and gamma radiation shielding for biological applications," Journal of Bionanoscience, vol. 12, no. 2, pp.170-176, 2018.

[20] Ahmed Hashim and Aseel Hadi, "A novel piezoelectric materials prepared from (carboxymethyl cellulose-starch) blend-metal oxide nanocomposites,” Sensor Letters, vol. 15, no. 12, pp. 1019-1022, 2017.

[21] Ahmed Hashim and Qassim Hadi, "Novel of (niobium carbide/polymer blend) nanocomposites: fabrication and characterization for pressure sensor," Sensor Letters, vol. 15, no. 11, pp. 1-3, 2017.

[22] Alaa J. Kadham, Dalal Hassan, Najlaa Mohammad, and Ahmed Hashim, "Fabrication of (polymer blendmagnesium oxide) nanoparticle and studying their optical properties for optoelectronic applications," Bulletin of Electrical Engineering and Informatics, vol. 7, no. 1, pp. 28-34, 2018.

[23] Ahmed Hashim and Zinah Sattar Hamad, "Synthesis, characterization and nanobiological application of (biodegradable polymers-titanium nitride) nanocomposites," Journal of Bionanoscience, vol. 12, no.4, pp. 504-507, 2018.

[24] Ahmed Hashim and Aseel Hadi, "Synthesis and characterization of $\left(\mathrm{MgO}-\mathrm{Y}_{2} \mathrm{O}_{3}-\mathrm{CuO}\right)$ nanocomposites for novel humidity sensor application," Sensor Letters, vol. 15, pp. 858-861, 2017.

[25] S. Harikrishnan and S. Kalaiselvam, "Experimental investigation of melting and solidification characterization of nanofluid as PCM for solar water heating system", International Journal of Emerging Technology and Advanced Engineering, vol. 3, pp. 628-635, 2013.

[26] S. Zhang, Q. Tao, Z. Wang, and Z. Zhang, "Controlled heat release of new thermal storage materials: the case of polyethylene glycol intercalated into graphene oxide paper," Journal of Materials Chemistry, vol. 22, pp. 20166-20169, 2012.

[27] J. Huang, S. Lu, X. Kong, S. Liu, and Y. li, "Form-stable phase change materials based on eutectic mixture of tetradecanol and fatty acids for building energy storage: Preparation and performance analysis," Journal of Materials, vol. 6, pp. 4758-4775, 2013. 